\title{
Richer but Resented: What do Cash Transfers do to Social Relations?
}

\author{
Ian MacAuslan and Nils Riemenschneider
}

\begin{abstract}
It is quite possible for statistical averages and human experiences to run in opposite directions. A per capita increase in quantitative factors may take place at the same time as a great qualitative disturbance in people's way of life, traditional relationships and sanctions. People may consume more goods and become less happy or less free at the same time.
\end{abstract}

(E.P. Thompson 1963, The Making of the English Working Class, Penguin: 231)

\begin{abstract}
Cash transfers are an increasingly important component of social protection systems in most countries. Usually, cash transfers are evaluated against their effects on poverty or human capital, with their impact on social relations within and between households relegated to discrete comments on 'stigma', 'resentment' and sharing, including reduction of remittances and other support. Using evidence from Oxford Policy Management's evaluations of cash transfer programmes in Malawi and Zimbabwe, we suggest reconceptualising cash transfers as ongoing processes of intervention in a complex system of social relations. Cash transfer interventions operate through and affect this system at each stage: awareness-raising, targeting, payment, case management and monitoring and evaluation. We conclude that the impact of cash transfers on social relations is large and often negative. We argue that this is intrinsically important for wellbeing, but can also have negative consequences for material aspects of wellbeing, such as livelihoods.
\end{abstract}

\begin{abstract}
1 Introduction
Cash transfer interventions form increasingly important parts of social protection systems in most countries. Following the cash benefits systems prevalent in most industrialised countries, many low- and middle-income countries have independently developed and implemented national cash transfer systems to provide social protection to vulnerable groups, such as older persons or families with children. At the same time, many donor agencies, international organisations and non-governmental organisations (NGOs) are funding cash transfer projects, with or without extensive government buy-in. These projects are usually of two types: parts of emergency responses (such as the Zimbabwe Emergency Cash Transfer programme) or pilot projects designed to encourage governments to develop national cash transfer programmes (such as the Hunger Safety Net Programme in Kenya or the Mchinji Social Cash Transfer Scheme in Malawi). Both donor-funded
\end{abstract}

and nationally run projects have been extensively evaluated, with largely positive results, leading to ever greater enthusiasm for and emphasis on cash transfers (Hanlon et al. 2010). This article argues that additional considerations, especially with respect to social relations, should be taken into account in assessing cash transfers.

Usually, cash transfers are evaluated principally against their first order effects on recipients' and non-recipients' consumption expenditure, income, nutrition, human capital (health and education) and labour supply. These effects can be called 'material impacts'. Some attention is also given to second order economic impacts, such as inflationary effects or economic multipliers (Davies and Davey 2008). These impacts are typically most interesting to donors and governments, possibly because they have the clearest links to economic growth. They are also relatively straightforward to measure with surveys. Generally, where markets are functional 
(so that supply responds to additional demand), these first order effects are positive in the aggregate, because recipients of cash transfers by and large spend them on useful goods and services without significantly reducing their labour supply. Viewed through this material lens, cash transfer programmes have received glowing evaluations (Arnold et al. 2011).

Many evaluations also assess the impact of cash transfers on social relations within and between households. Findings are mixed. Some assessments note positive effects on social capital (Attanasio et al. 2009), self-confidence and social status (World Bank 2008), or find that cash transfers did not increase domestic violence (Thakur et al. 2009). Although resentment towards recipients of cash transfers has been identified (Ellis 2008), negative findings are normally less commonly presented and are often constituted as discrete comments on 'stigma', 'resentment' and sharing, such as reduction of support, including remittances.

However, impacts of cash transfers on social relations are far more profound and important than most assessments discuss. This is for two reasons.

First, few evaluations examine the impacts on wellbeing beyond 'material' factors (income, education, etc.). Wellbeing also has 'relational' and 'symbolic' dimensions, constituted in networks or status, for instance. These dimensions can be central to people's judgements of development interventions, and can have secondary impacts on material dimensions, but are rarely central to cash transfer design or evaluation.

Second, cash transfer programmes not only provide cash but, like most development programmes, are pervasive interventions in people's lives. They involve many other processes that affect social relations. These other processes include initial mobilisation, targeting, registration, payment, communications and, often, monitoring and evaluation. These are rarely examined but are important. For example, mobilisation that takes place through a specific individual (such as a chief or health worker) can imbue that individual with substantial power, changing their relationship with others. Alternatively, targeting can cause suspicion and jealousy and erode shared cultural values. This directly reduces wellbeing but can also have secondary impacts on material aspects of wellbeing if people share less or cooperate less.

We propose a theoretical framework for assessing impact on non-material dimensions of wellbeing in the next section, then illustrate these points with examples from Malawi and Zimbabwe.

\section{A framework for the analysis of wellbeing}

To analyse 'non-material' impacts, we propose a framework for the analysis of wellbeing. The basic premise is that wellbeing - the improvement of which should be the goal of development interventions - depends on more than just the possession of or interaction with material objects or characteristics. It also depends on relations with people and relations with ideas. This notion of wellbeing is not universal but local, subjective and rooted in culture and personal experience (White and Ellison 2007), and in this sense, tallies with a 'rights first' approach to development that prioritises local constructions of wellbeing (Copestake 2007).

Very briefly, this framework includes not only 'material' but also 'relational' and 'symbolic' dimensions. Material dimensions of wellbeing refer to the types of impacts that are usually assessed, such as income and basic needs. Relational dimensions refer to autonomy and inclusion in social networks and processes. Symbolic dimensions refer to rights, self-reliance, status (e.g. the role of the headman may be elevated by an NGO) and a sense of 'belonging'.

We join Copestake (2008: 548) to argue that:

analysing [development] programmes solely with respect to material wellbeing, while important, can be misleading because it fails to capture their full meaning to intended beneficiaries and to other stakeholders. Any social assistance programme is embedded within a web of social relationships that is moulded in turn by strongly held beliefs and values. These influence how it is perceived by different stakeholders, how it operates in practice, scope for its reform and ultimately its effect on material wellbeing as well.

We now apply this approach to two case studies. Both have significant non-material impacts, and greater consideration of these impacts may alter 
evaluative judgements about the programmes. An analysis of relational impacts allows us to focus on how cash transfers affect social relations and to show how these impacts are important intrinsic components of wellbeing (sometimes considered just as important as material impacts by programme participants), as well as having consequences for material dimensions of wellbeing. Symbolic impacts are likely to be important for the legitimacy of programme implementers, including the government or its representatives, suggesting a link between cash transfers and state-citizen relationships (De la O Torres 2010). Bearing these impacts in mind, a 'rights first' approach to development would imply greater consultation with potential participants before intervening in their lives.

\section{Mchinji Social Cash Transfer (MSCT) Scheme, Malawi}

The MSCT consists of small regular cash payments to particularly vulnerable labourconstrained households, which are selected through a community process. The goal of the MSCT is to contribute to national efforts to reduce poverty and hunger in ultra-poor households, increase school enrolment and attendance and improve the health, nutrition, protection and wellbeing of orphaned and other vulnerable children. There are thus clear objectives with respect to material impacts (health, education, wellbeing and poverty), but not for relational or symbolic impacts.

Boston University carried out an evaluation of the Mchinji Scheme in 2007/08 (Miller et al. 2008), consisting of three rounds of quantitative surveys and a qualitative study. Oxford Policy Management (OPM) carried out a qualitative study for the World Bank to compare cash transfer schemes to social action funds. We carried out 40 focus groups with men, women, HIV-positive men and HIV-positive women in ten communities (Riemenschneider et al. 2008). Three rounds of a quantitative survey were also carried out.

Results point in a clear direction of positive change with respect to material impacts. Survey findings included improved health, higher demand for health care, increased expenditure on education, reduction in child labour, accumulation of household assets, productive assets, livestock and improved housing, greater production and greater food diversity. Focus group respondents reported improvements in 'basic needs coverage, human capital investments, as well as investment in assets and productive activities' (Riemenschneider et al. 2008). Boston University's qualitative evaluation found the perceived impact among recipients to be dramatic at times. An HIV-positive mother said that the transfer allowed her to pay for the bus fare to the health clinic where she gets free AIDS medication. Without the transfer she would be dead and her children would have no mother, she said. With respect to first order 'material' impacts, therefore, the MSCT appears to have been successful.

The MSCT had no explicit relational objectives and the impact on social relations is mixed. On the one hand, aspects of the intervention helped to improve social relations. There was a 'greater willingness to befriend recipients of cash transfers', and the programme relieved 'community members of having to support the very poor' (Riemenschneider et al. 2008). On the other hand, aspects of the targeting procedure (among other aspects) appear to have affected social relations negatively in some communities. The targeting process is elaborate and involves the community at critical points.

The role of the headman includes signing off the list of vulnerable and labour-constrained households that a community Social Protection Committee has prepared and which is later laid before the community for approval and then checked by district authorities. Findings suggest that there was unease about the involvement of the headman. Examples of favouritism were cited by focus group members. This extended even to committee members: focus group participants felt that friends and relatives of committee members were selected, rather than the most vulnerable. A common view was that support should go directly to the intended beneficiary to avoid this kind of problem. Some selected households were said to have claimed to have orphans to support but in reality had none. In this way, the MSCT has an unintended effect on social relations. On the face of it, the MSCT strengthens the position of the headman and of committee members while it also fosters resentment against them. Other cash transfer programmes avoid the involvement of community leaders by using 'objective' criteria for targeting (such as age). 
Another concern applies to many targeted cash transfer schemes: some community members are chosen, while others are not. In the case of the MSCT, at a community gathering all households were ranked according to their vulnerability status, and the most vulnerable 10 per cent were selected to receive cash transfers. Targeting singles out individual households and hence affects their relations with other households. Consider the second most vulnerable 10 per cent of households. They are almost as vulnerable as the lowest decile, but do not receive the transfers.

There is no obvious solution. A non-targeted programme is a universal programme, which either excludes entire non-targeted communities or (in this case) is about ten times as expensive. Yet, in an environment where membership of a collective is more important than individual advancement, the targeting of individual households may run counter to the perceptions of people in the targeted villages. 'We are all poor' was a common sentiment among focus group participants in our research (see also Ellis 2008). On that basis, the distinction that some received the benefit while others did not could well have seemed arbitrary. The resentment and increased conflict that recipients reported may be a consequence of this.

These findings suggest that social relations should be carefully taken into account when designing, implementing and evaluating cash transfer schemes.

\section{Zimbabwe Emergency Cash Transfer (ZECT)}

ZECT was a pilot project implemented by Concern Worldwide and funded by the World Food Programme (WFP) that sought to test the replacement of food aid with an equivalent amount of cash. ZECT operated for five months between November 2009 and March 2010, providing cash only (around US $\$ 7$ per person), food only ( $10 \mathrm{~kg}$ cereals, $1.8 \mathrm{~kg}$ beans and 0.6 litres oil per person) or a mixture of cash and food to up to 58,866 individuals on a monthly basis. The objective of ZECT was principally material and research-based: to enable households to meet their food entitlements, to understand market responses to cash, and to understand community responses to cash transfers.

ZECT was carefully planned from a technical point of view. Shortly before the project was launched, Zimbabwe suffered from hyperinflation that had catastrophic effects on the economy and led to the replacement of the Zimbabwean dollar by the United States dollar. At the same time, the maize market was deregulated. Markets began to function better as the economy recovered, suppliers regained confidence that their goods would be exchanged for a valuable currency, and buyers became more accustomed to trust the currency. Nonetheless, considerable nervousness about markets remained, and many preferred to retain large foodstocks rather than sell and rely on their ability to buy back later. Concern Worldwide therefore engaged in a careful assessment of the functioning of local markets before implementing the cash transfer intervention, and transfers were made in US dollars.

The following impact results come from an evaluation conducted by OPM (Kardan $e t$ al. 2010), which used participatory methods (community scoring), focus groups and semistructured interviews with recipients, nonrecipients and knowledgeable individuals (doctors, teachers, chiefs, Concern staff). In scoring exercises, participants agreed on the size of impact, and how important this was to them (out of a score of ten). Evaluation teams visited three villages (one from each transfer type) in each of three districts. Results were triangulated with Concern staff and with Concern's own monitoring and evaluation (M\&E) reports.

The provision of cash was broadly successful in terms of material impacts. Markets worked well, so recipients were able to use the cash to buy maize-meal (the main staple) with little problem. Neither the evaluation nor Concern's monitoring identified substantial inflation caused by the transfer. Supply in local maize markets increased in response to the transfer. Kardan et al. (2010: 41) concluded that 'cash had the highest impact on staple consumption'. Participants in scoring found this very important (ten out of ten). Cash recipients interviewed for the evaluation reported spending more on health and education (confirming $\mathrm{M} \& \mathrm{E}$ reports), once their food needs were met. This was considered important (9.7 out of 10). Recipients reported that cash had a small positive impact on the purchase of basic goods, but that this was not substantial (5 per cent of cash spending according to M\&E reports), and comparatively unimportant to them (7 out of 10). 
Set against these positive material impacts were some more ambiguous relational impacts. The programme evaluation found that relational impacts, both within and between households, were very important to respondents. Intrahousehold relations and food consumption were the only categories to receive a score of ten out of ten from each focus group in terms of importance. Community relations were the third most important category of impact, behind education and health. This indicates that relational impacts seem to be just as important to recipients as material impacts.

The cash transfer appeared to improve relations within recipient households. Respondents said that 'people lived in harmony because there was enough food in the house' (Kardan et al. 2010: 50). However, respondents were clear that cash had negative consequences for relations between households: 'when cash was given to recipients, jealousy brewed easily because people did not like sharing cash, but there was no hatred when there was food' (recipients in Nyanga, cited in Kardan et al. 2010: 48). The aversion to sharing cash is a cultural practice, common throughout the world, and was in contrast to the provision of food, which had a positive impact on social relations, because food is usually shared. This raises important questions for the desirability of alternative forms of transfer.

Focus group respondents felt the negative impact of cash on social relations to be intrinsically very important. Moreover, respondents were clear that poor relations with their neighbours subsequently had negative material impacts. For example, the normal way to deal with temporary food shortages is to share with neighbours affected by shocks. However, this relies on good relations since it is based on trust that the household will reciprocate. Second, neighbours share agriculture inputs and this is critical for production. Third, neighbours share childcare when household members travel for casual labour. Fourth, households engage in joint community work to build shared assets.

It was not only the provision of cash that had negative consequences for social relations, but also the process of targeting people (see also Ellis 2008). Some respondents felt that community-based targeting - in essence asking the community to select some and not others - caused tensions that even led to deaths through witchcraft, as non-selected households put curses on recipients. Where food was distributed, this tension was mitigated because people shared the food, but this did not occur with cash. Nonrecipients also claimed that the communitybased process led to selection of people with wide social networks. This is because in practice, people were selected on the basis of voting for others who were considered vulnerable. As the evaluation (Kardan et al. 2010: 72) points out:

The major weakness in this system is that in a communal setting, it is very hard for marginalised households to speak freely, and relatively easy for powerful households to secure nominations and validations from those in their social network. This does not indicate that no vulnerable households are selected: to the contrary, many are. It does suggest, however, that some non-vulnerable households will be included, and some vulnerable households will be excluded because they are vulnerable not only economically but also socially and politically. This is even more likely to be the case where villages are strongly divided along political lines, as was the case in one fieldwork village.

The dislike of targeting was so strong - and its negative consequences felt by recipients and non-recipients alike - that all recipients asked would have preferred everyone in the village to receive an equal share, even if this was less than their current allocation. They preferred to be less rich, and less resented. This striking finding is testament to the importance of relational aspects of wellbeing.

The challenge for policymaking in Zimbabwe is how to respond to these findings. Concern, in particular, are juggling a perceived need to respond to a food emergency with limited resources, against calls from recipients to make equal distributions. It is vital to assess whether the transfers are necessary from a material humanitarian point of view, before implementing targeted cash transfers that may damage social relations.

As with most evaluations, the symbolic impacts of ZECT were not examined, but several potential symbolic consequences could have been explored. First, the decision to switch from food 
to cash was taken with great 'technocratic care' (e.g. checking that markets would respond), with positive consequences in many ways, but without the involvement of communities. This decisionmaking procedure must have contributed to a feeling that households in this area were not involved in processes that have important consequences for their lives. Second, the targeting process probably strengthened the symbolic role of the village leaders, as they were asked to mediate the targeting.

Third, the distribution process made use of the normal symbols of power to distribute the cash and food, including schools, NGO personnel and security officers, and as a result probably strengthened these institutions. Finally, the individualisation of people and households (i.e. individuals in households satisfy their own needs, and households do not share) raised by the transfer of cash, may have wider symbolic consequences. There are anthropological accounts of the introduction of currency eroding traditional exchange mechanisms, and in a similar way, cash transfers may erode rather than reinforce shared consciousness and activity, with irreversible negative consequences.

\section{Conclusions}

Cash transfers leave recipients richer, but through their various processes also change people's relationships. Does this matter? If development interventions are to be judged by their impact on wellbeing, and wellbeing is not only material but also includes the nature of relationships with other people, institutions and symbols, then these changes must matter. Cash transfers are usually designed and evaluated with a focus on material impacts, with social relations considered less centrally. This focus, we have argued, misses important aspects of the impact of cash transfers.

\section{References}

Arnold, C., with Conway, T. and Greenslade, M. (2011) Cash Transfers Evidence Paper, DFID Policy Division Evidence Paper, London: Department for International Development Attanasio, O.; Pellerano, L. and Reyes, S.P. (2009) 'Building Trust? Conditional Cash Transfer Programmes and Social Capital', Fiscal Studies 30.2

Copestake, J. (2008) 'Multiple Dimensions of Social Assistance: The Case of Peru's "Glass
We have shown that targeting and the distribution of cash in Zimbabwe has led to resentment and tension that participants considered just as significant as having enough food, and that because of this, they preferred less cash provided it was delivered equally to everyone. In Malawi, we have seen that the mobilisation and targeting processes both strengthened the position of the headman and generated substantial resentment.

The need to incorporate non-material impacts and a process view is not specific to cash transfers. On the contrary, these approaches should be applied to all development interventions. Explicitly considering the views of participants on non-material impacts does not make choices simpler or generate unambiguous conclusions: as the Malawi and Zimbabwe case studies show, material and relational wellbeing may pull in opposite directions.

It follows that the current enthusiasm for social cash transfers should be tempered with some consideration of impacts on the quality of people's relationships. The framework of material, relational and symbolic aspects of wellbeing allows us to do this by making explicit the importance of non-material dimensions of wellbeing, and by helping to identify the linkages between different aspects of wellbeing. This framework should be applied in the design, implementation and evaluation of all social protection programmes, to ensure that judgements about their suitability are based on a comprehensive assessment of what matters for improving people's lives and to avoid, in Thompson's words, 'a great qualitative disturbance in people's way of life, traditional relationships and sanctions'.

of Milk” Programme', Journal of Development Studies 44.4: 545-61

Copestake, J. (2007) 'Poverty and Exclusion, Resources and Relationships: Theorising the Links between Economic and Social Development', in I.R. Gough and J.A. McGregor (eds), Wellbeing in Developing Countries: From Theory to Research, Cambridge: Cambridge University Press: 199-2 16

Davies, S. and Davey, J. (2008) 'A Regional Multiplier Approach to Estimating the Impact 
of Cash Transfers on the Market: The Case of Rural Malawi', Development Policy Review 26.1: 91-111

De la O Torres, A. (2010) The Politics of Conditional Cash Transfers, New Haven: Yale University Press

Ellis, F. (2008) 'We Are All Poor Here: Economic Difference, Social Divisiveness, and Targeting Cash Transfers in Sub-Saharan Africa', paper prepared for the Social Protection for the Poorest in Africa: Learning from Experience Conference, Uganda, 8-10 September

Hanlon, J.; Barrientos, A. and Hulme, D. (2010), Just Give Money to the Poor: The Development Revolution from the Global South, Sterling VA: Kumarian Press

Kardan, A.; MacAuslan, I. and Marimo, N. (2010) Evaluation of Zimbabwe's Emergency Cash Transfer Programme, report for Concern Worldwide, Harare, www.concern.net/sites/ concern.net/files/cash_transfer_project_ zimbabwe_2009.pdf (accessed 13 September 2011)

Miller, C.; Tsoka, M. and Reichert, K. (2008) Impact Evaluation Report: External Evaluation of the Mchinji Social Cash Transfer Pilot, Boston: Center for International Health and Development, Boston University School of Public Health and Zomba: Centre for Social Research, University of Malawi

Riemenschneider, N.; MacAuslan, I. and Brook, S. (2008) Malawi/Uganda - Social Protection and HIV/AIDS: When are Community Level

Interventions Appropriate?, report for the World Bank, Oxford: Oxford Policy Management

Thakur, S.; Arnold, C. and Johnson, T. (2009) 'Gender and Social Protection', in OECD, Promoting Pro-Poor Growth: Social Protection, Paris: Organisation for Economic Cooperation and Development

White, S. and Ellison, M. (2007) 'Wellbeing, Livelihoods and Resources in Social Practice', in I.R. Gough and J.A. McGregor (eds), Wellbeing in Developing Countries: From Theory to Research, Cambridge: Cambridge University Press: $157-75$

World Bank (2008) For Promotion and Protection: The Design and Implementation of Effective Safety Nets, Washington DC: World Bank 